\section{HUMAN ECOLOGICAL GENETICS}

The Biology of Human Adaptability

Edited by Paul T. Baker and J. S. Weiner. Pp. viii +541. (Oxford: Clarendon Press; London: Oxford University Press, 1966.) 105s. net.

The Biology of Human Adaptability originated from a symposium entitled "The Biology of Populations of Anthropological Interest" organized jointly by the International Biological Programme and the Wenner-Gren Foundation for Anthropological Research, and held in Burg-Wartenstein in 1964. In his foreword, Sir Lindor Brown points out that the purpose of the symposium was to review the present state of knowledge in the general field of studies on human adaptability being planned in connexion with the International Biological Programme. To this end, nineteen authors have contributed eighteen chapters conveniently arranged in sections on African, American, Asian, Cireumpolar and High Altitude populations, together with an introductory section; the range of their interests is wide, and there are chapters by geneticists, anthropologists, anatomists, paediatricians, physicians and physiologists.

The book certainly fulfils its major purpose, for even the most cursory examination reveals more of what is not known about people than what is known. Nor is time on our side in this matter, for as Neel and Salzano on South American Indian populations and Sanghvi on Indian tribes point out, the rate of cultural invasion of these areas is so great that shortly there will be removed for good the possibility of studying these primitive groups.

The contributions to the book vary a good deal in quality. There are excellent chapters of methodology by Schull and Ainsworth Harrison. Kirk reports many interesting genetical data from Australia and Now Guinea, as do Sanghvi from India, Edholm from South-Westerr Asia, Laughlin from Circumpolar and Tobias from Southern African populations. Though Tanner's chapter on growth and physique is excellent, some of the others, particularly those concerned with physiological investigations, are less convincing. As might be expected, even primitive peoples are skilled in making effective cultural adaptations to climatic stress so that several investigations have failed to demonstrate different capacities to adapt to extreme heat and cold, for example. So far, there is compelling evidence for genetic adaptation only in respect of hypoxia at high altitudes. Even negative evidence has its value, however, for it underlines the importance of knowing about cultural practices in undertaking an analysis of physiological (and, for that matter, genetical) characters; in short, the value-indeed the need-for an interdisciplinary approach to problems of human diversity.

The editors are to be congratulated on producing this interesting volume which appears to be commondably free of errors. It will be of interest to those professionally concerned as well as to laymen.

M. J. LAWRENCE

\section{BACTERIAL GENETICS}

\section{Bacterial Genetics}

By Werner Braun. Second edition. Pp. xiii +380 . (Philadelphia and London: W. B. Saunders Company, 1965.) $70 s$.

BACTERIAL genetics has changed almost beyond recognition in the thirteen years since the first edition of this book; so now has the book. Although there are only sixty per cent more pages, the second edition contains incomparably more material than the first. Dr. Braun has a gift for concise description, and often conveys the essentials of complex series of experiments in a surprisingly short space.
The book covers, of course, the familiar three methods of genetic transfer but, while mentioning the fragmentary information available on the genetics of Vibrio and Pseudomonas, it disappointingly omits any description of the genetic system of Streptomyces. There is a particularly extensive treatment of genetic phenomena leading to population changes, and the well stocked menagerie of mutants will provide useful reference material for the many of us who entered bacterial genetics with no formal training in bacteriology. Mutagenesis, especially its nonadaptivity, is treated well; there is a nicely illustrated and concise account of bacterial cytology, and two economical chapters covering transcription, translation and their regulation.

Dr. Braun has a very individual view of geneticists (witness the final paragraph of Chapter I) and is somewhat ill at ease about standard genetic concepts, which he appears to consider in some way out of date. ("Genes located at corresponding sites of homologous chromosomes ... . were [sic] referred to as alleles"-p. 34.) His account of crossing-over in Chapter 12 has misleading diagrams, and it seems a pity to introduce the unnecessary complexities of a diploid life cycle when a haploid eukaryote would have served the purpose better. Lmbarrassment at defining and then using the word "gene" leads to endless circumlocutions ("blocks of separate nucleotide sequences in the DNA molecule"--p. 81). The author no doubt seeks to make it easier for the nongeneticist to follow the book by these devices, but he seems to increase the possibilities of misunderstanding. The merits of the book, however, far outweigh its minor irritations.

D. A. Hopwood

\section{BACTERIAL RECOMBINATION AND DNA}

\section{Proceedings of the Symposium on Bacterial Trans- formation and Bacteriocinogeny}

August 13-16, 1963, Budapest. (Symposia Biologicid Hungarica, Vol. 6.) Pp. 167. (Budapest: Akadémiai Kiadô, 1966.) $42 s$.

THE symposium contributions collected together in this volume reflect the range of experimental techniques, from the simple to the highly sophisticated, which are being used to study bacterial transformation systems, bacteriocins and the functioning of molecules of DNA in their cellular environment. The participants came from eight different countries and several of the 22 papers are substantial: some are of the review type and others report new work in detail for the first time. Other contributors gave short reports of experiments under way at the time of the symposium (1963).

The overall process of "transformation" is now well documented, at least for certain Gram positive bacteria, and the time has now come to study the constituent parts of this phenomenon. Szybalski and Opara-Kubinska concentrated on structural aspects of defined genetic marker regions of the donor DNA and, in addition to preliminary results concerning Bacillus subtilis, gave an excellent review of the ways in which donor DNA may be labellod so that it can be subsequently recognized in the transformed bacteria. The factors controlling competence (and hence the entry of donor DNA) are still only vaguely understood. Some progress has been made by Pakula, however, who induced competence in streptococei by means of a preparation, apparently an enzyme, isolated from the culture filtrates of these bacteria. In pneumococci, Kohoutová asserted that potassium ions are required for the irreversible fixation of the transforming DNA and that DNase may function at some stage in the transformation process. At the molecular level, recombination between the incoming DNA and the host DNA was analysed by Hotchkiss, who gave a lucid account of the 